\title{
reviscafuences
}

ISSN: $1575-7072$ | e-ISSN: 2172-7775

Páginas: $53-64$

Recibido: 2019-03-29

Revisado: 2019-12-05

Aceptado: 2019-12-13

Preprint: 2020-04-20

Publicación Final: 2020-06-15 www.revistascientificas.us.es/index.php/fuentes/index

DOI: https://doi.org/10.12795/revistafuentes.2020.v22.i1.05

\section{Acompañamiento sociopedagógico, holismo y longitudinalidad: Claves de una buena práctica con un menor infractor}

\section{Socio-pedagogical accompaniment, holism and longitudinality: Keys from a good practice with a young offender}

\author{
(iD) David Herrera-Pastor \\ Universidad de Málaga (España) \\ (iD) María Teresa Padilla-Carmona \\ Universidad de Sevilla (España) \\ (iD) José González-Monteagudo \\ Universidad de Sevilla (España)
}

\section{Resumen}

Este artículo se destila de una investigación llevada a cabo en torno al excepcional caso de Omar, un menor infractor que se convirtió en educador de menores debido, fundamentalmente, al proceso de reforma juvenil que le impuso el sistema de justicia español. El foco de este escrito se centra en escudriñar algunas de las claves esenciales de aquella buena práctica. Para llevar a cabo la investigación se utilizó la metodología biográfica, utilizando el modelo de relatos cruzados. Las principales fuentes de información fueron: a) Omar y otros diecisiete personajes clave (la jueza del caso, el subdirector del centro de internamiento, su tutora de libertad vigilada, su madre de acogida en España, etc.). b) Sus expedientes en el Juzgado de Menores y en la Dirección General de Reforma Juvenil. Y c) un amplio registro fotográfico, fundamentalmente, de su experiencia en el centro de internamiento. El análisis se enfoca sobre: 1) el acompañamiento sociopedagógico llevado a cabo, 2) el carácter holístico de la intervención y 3) su longitudinalidad. Y se centra en la intervención desarrollada por la trabajadora social del centro de internamiento, que fue la piedra angular de todo el proceso de reforma juvenil (no solo de la medida judicial de la que oficialmente formaba parte). En las conclusiones se especifica: 1) Por qué el acompañamiento sociopedagógico es muy adecuado para este tipo de casos. 2) Que se puede transformar más fácilmente al individuo si se adecuan sus circunstancias. Y 3) que la interseccionalidad debe ser coordinada durante todo el proceso.

\begin{abstract}
This article is distilled from a research carried out around the exceptional case of Omar, a young offender who became an educator of minors mainly due to the youth rehabilitation process imposed on him by the Spanish justice system. The focus of this paper is on exploring some of the essential keys to that good practice. The biographical methodology was used to carry out the research, using the cross-account model. The main sources of information were: a) Omar and seventeen other key figures (the judge in the case, the deputy director of the detention centre, his tutor on probation, his foster mother in Spain, etc.). b) His files in the Juvenile Court and in the Juvenile Justice System. And c) a broad photographic record, fundamentally, of his experience in the detention centre. The analysis focuses on: 1) the sociopedagogical accompaniment carried out, 2) the holistic character of the intervention, and 3) its longitudinality. And it focuses on the intervention developed by the social worker at the detention centre, which was the cornerstone of the whole youth rehabilitation process (not just the order of which she was officially a part). The conclusions specify: 1) Why sociopedagogical accompaniment is very appropriate for this type of cases. 2) That the individual can be more easily transformed if his or her circumstances are appropriate. And 3) that intersectionality must be coordinated throughout the process.
\end{abstract}

\section{Palabras clave / Keywords}

proceso de aprendizaje; delincuencia juvenil; niño desfavorecido; mentoría; enfoque interdisciplinario; desarrollo de la educación; biografía.

learning processes; juvenile delinquency youth; disadvantaged children; mentoring; interdisciplinary approach; development education; biographies. 


\section{Introducción}

Este artículo se destila de la investigación realizada en torno al caso de Omar, un joven argelino que siendo menor de edad y estando en situación irregular fue detenido en España por cometer un delito de tráfico de drogas. Como consecuencia, el sistema de Justicia Juvenil le impuso un proceso de reforma de veinticuatro meses, que se dividió en dos medidas: la primera, internamiento en centro (de régimen semiabierto) y, la segunda, libertad vigilada. Antes de concluir esta última, comenzó a trabajar en un piso tutelado de protección de menores, al principio como monitor y más tarde como educador. Allí lleva trabajando desde entonces (hace más de quince años), donde se ha convertido en uno de los profesionales de referencia.

Uno de los motivos principales que animaron la puesta en marcha de la investigación, fue la evolución del caso. Pasó de menor infractor a educador de menores, prácticamente, durante el transcurso del proceso de reforma juvenil. En virtud de ello, se establecieron dos focos en la investigación. Por un lado, qué había ocurrido a lo largo de dicho proceso de reforma para que se suscitase aquella transformación. Y, por otro lado, qué había tenido de educativo todo aquel proceso. Para responder a aquellas preguntas y posibilitar un análisis exhaustivo, se decidió utilizar la metodología de investigación biográfica, que era la que mejor se adecuaba a las características y propósitos del estudio.

El trabajo de campo se materializó recurriendo a distintas fuentes de información y utilizando diversas técnicas de recogida de datos. Además de entrevistar a Omar en numerosas ocasiones, se entrevistaron a diecisiete personajes que fueron significativos en el desarrollo de su historia: la jueza de menores, el subdirector del Centro de Internamiento de Menores Infractores (CIMI), la trabajadora social del CIMI, su tutor en el CIMI, su tutora durante la libertad vigilada, su madre de acogida, su hermano biológico, un compañero de trabajo, etc. También se recabó un registro documental con toda la documentación de sus expedientes en el Juzgado de Menores y en la Dirección General de Reforma Juvenil. Así como un extenso registro iconográfico que, principalmente, ilustraba experiencias acaecidas durante la medida de internamiento en centro. En definitiva, se recopiló un compendio de información cuantiosa y plural que permitió construir para la ocasión un relato biográfico riguroso, completo y polifónico, que dio la posibilidad de comprender la realidad de Omar desde todas sus aristas. Dicho relato fue construido de acuerdo al modelo de relatos cruzados. La categorización se realizó de manera emergente. Y se utilizó el programa informático NVivo para realizar el análisis de los datos. De manera específica, en el presente artículo se analizan varios de los elementos que se consideraron esenciales en la buena práctica llevada a cabo con Omar. A continuación, se relacionan:

1. Por un lado, la concepción de acompañamiento sociopedagógico que predominó durante la intervención. Se comprendía que el educando era el protagonista de la situación y quien, de manera proactiva, debía transformar su situación. Los profesionales no deben dar el trabajo hecho al educando, sino intentar crear las condiciones que le proporcionen la posibilidad de conseguirlo (ha de ser él o ella su principal artífice). En virtud de ello, se podría decir que los profesionales son, entre otras cosas, procuradores de situaciones que intentan ayudar al sujeto a conseguir los objetivos.

2. Por otro lado, el carácter holístico del proceso. La intervención abordaba cuantos aspectos se consideraban necesarios (pedagógicos, laborales, económicos, sociales, etc.), independientemente de la esfera de que se tratase. En el caso de Omar se le ayudó a conseguir el graduado escolar, un empleo, una familia de acogida y a configurar un círculo social desvinculado del mundo del tráfico de drogas.

3. Y, por último, longitudinalidad. Fue trascendental que hubiese una persona acompañando el proceso desde su inicio hasta su fin. Resulta necesario que haya continuidad y coherencia durante toda la intervención.

Todo ello se va a analizar a través de la intervención que llevó a cabo la trabajadora social del centro de internamiento, que fue la persona que: realizó un seguimiento de las distintas acciones que se ponían en marcha con Omar para que fuesen en la misma línea a lo largo de todo el proceso de reforma juvenil (incluso cuando este ya había pasado a libertad vigilada); puso en marcha iniciativas de diversa naturaleza, que ilustran el carácter holístico de la intervención; y, transversalmente, materializó el acompañamiento sociopedagógico que aquí se reivindica.

1 Ente de la Consejería de Justicia de la Comunidad Autónoma de Andalucía, encargado de, fundamentalmente, materializar las medidas judiciales que se imponen a los menores. 
Las principales ideas que se sacan en claro son: 1) que el acompañamiento sociopedagógico es un modelo muy adecuado para intervenir en casos complejos de menores en situación de riesgo. La confianza y el estímulo son dos de sus rasgos fundamentales. 2) El enfoque complejo y ecológico debe ser co-sustancial a todo el proceso. Transformar las circunstancias es tanto o más importante que transformar al individuo. Y 3 ) la interseccionalidad coordinada y con sentido se debe procurar durante todo el proceso.

\section{Marco teórico: Acompañamiento sociopedagógico, holismo y longitudinalidad}

En este apartado se hace una revisión de los tres conceptos sobre los que se ha puesto el foco en este artículo. Se comienza por acompañamiento sociopedagógico, porque se entiende de manera transversal y como el marco en el que se inscriben los otros dos: holismo y longitudinalidad.

\subsection{Acompañamiento sociopedagógico}

Para explicar la concepción contemporánea de acompañamiento sociopedagógico, hay que retroceder hasta el origen del término Pedagogo, que nació en la antigua Grecia y se refería a la persona que acompañaba y apoyaba al niño en las distintas tareas, fundamentalmente, formativas. Salvando las distancias, en la actualidad se mantienen ciertas similitudes. El acompañante suele ser un adulto (generalmente un profesional) cuya función es compartir un trayecto de la vida del educando, en la que opera como mentor (Alonso y Funes, 2009), para contribuir en el desarrollo de una o varias de sus dimensiones personales.

El acompañante como educador (o el educador como acompañante) es una persona adulta que contribuye con sus competencias y bagaje experiencial al itinerario de crecimiento personal y social de las personas y grupos en el proceso educativo. La persona adulta aporta su crítica constructivista, su trayectoria y su empatía para estimular al grupo y al individuo a que construya su propio proyecto

(Mendia, 2013, en García-Pérez y Mendía, 2015, p. 44).

En concreto, es un medio de construcción muy recomendable para ayudar al educando a desarrollarse (Vallés y Pérez Juste, 2015), para que sepa desenvolverse en todos los ámbitos (Puerta, 2016), de manera particular, en aquellos sobre los que se esté trabajando de un modo específico.

Y es que el acompañante debe plantearse horizontes (objetivos) con el educando (Batlle, 2010). Y, por tanto, diseñar y materializar propuestas para alcanzar sus metas. Durante el acompañamiento se deben procurar situaciones estimulantes que intenten provocar la evolución y desarrollo del sujeto. En lo posible, las propuestas deben ser planteadas de manera participada, pues la relación con el educando debe construirse, sabiendo del rol distinto que juega cada uno, pero, en lo posible, evitando imposiciones.

Acompañar significa conducir (dirigir), guiar (aconsejar, orientar) y escoltar (proteger) (Ghouali, 2007). También quiere decir caminar junto a otro (Planella, 2008). Lo que se ha traducir, por un lado, en apoyo del acompañante, que ha de ser sentido por el educando. Y, por otro lado, en protagonismo del sujeto. El educador debe recorrer el camino al lado del educando sin invadir su espacio de experimentación.

La relación que se establezca entre acompañante y educando resulta esencial para que este último evolucione satisfactoriamente. El vínculo entre ambos será el eje que moverá el proceso (Martínez, 2012). Según Vygotsky las relaciones entre las personas permanecen por encima de los procesos mentales (1962). Por tanto, el tipo de relación entre ambos es una de las claves de éxito de la intervención (Biagioli, 2018; Navarro, Uceda y Pérez, 2014).

Y uno de los pilares fundamentales de esa relación es el afecto. La conexión que se forje entre los actores mediará la disposición para afectar y dejarse afectar por el otro. Por eso hay que cultivar dicho vínculo entre ambos (Bowlby, 1976), porque condicionará, de manera sustancial, el desarrollo del proceso.

La confianza es otro de los elementos centrales que se ha de trabajar en la relación sociopedagógica (Boroel, Sánchez, Morales y Henríquez, 2018; Herrera y De Oña, 2016). Por un lado, el pedagogo debe confiar en los menores con los que trabaje, y hacer que ellos lo sientan. Y, por otro lado, debe ganarse su confianza con el trabajo diario y desde el con-tacto (tocarse de manera sensible) humanístico. 
"Yo soy yo y mi circunstancia, y si no la salvo a ella no me salvo yo" (Ortega y Gasset, 1914)

El ser humano no es solo individualidad, además es producto de las circunstancias. Por eso, cada caso hay que comprenderlo desde una perspectiva holística e interseccional (Konstantoni, Kustatscher y Emejulu, 2017), atendiendo a todos los elementos que lo conforman. Cada persona se encuentra inmersa en unas situaciones determinadas y, como consecuencia, recibe una serie de influjos que mediatizan su desarrollo. Será complicado influir, de manera relevante, en el desarrollo de un sujeto, si no se atiende a sus circunstancias (Herrera y De Oña, 2017). Las acciones sociopedagógicas que no tengan en cuenta los distintos elementos que configuran el mundo del sujeto (y condicionan su evolución), difícilmente tendrán trascendencia. Mucho menos en el ámbito de los menores infractores, donde las situaciones suelen ser tan complejas.

Cada caso se ha de abordar, por tanto, intentando conocer al menor y su circunstancia. Porque, utilizando términos de Ortega (1914), no se le podrá ayudar a "salvarse", si no se contribuye a transformar aquello que le lleva a cometer los quebrantamientos. Y eso se consigue desde una aproximación holística, implementando una acción integral que responda a las distintas necesidades que se planteen. Los enfoques fragmentados y lineales son parciales e incompletos. Por eso, para este tipo de ámbitos se reivindican, primordialmente, abordajes complejos e interdisciplinares (Colom y Núñez, 2001).

En ese sentido, el proceso de reforma juvenil ha de ser comprendido como un todo, y las distintas aportaciones se deben incorporar a él con sentido y coherencia. Las diversas acciones han de ir en la misma dirección. A la que hay que incorporar cuantos elementos sean requeridos.

La intervención holística e integral es una trama con vida propia, que fluctúa de manera singular en cada caso. Un proceso sinérgico en el que se deberían aprovechar las potencialidades de distintos agentes (de variados departamentos, disciplinas, etc.) con el propósito de que el sujeto evolucione.

El proceso de reforma juvenil, por tanto, se debe pensar y llevar a cabo desde una perspectiva ecológica. La tarea que se ha de materializar debe procurar la conjugación armónica y significativa de una sinfonía de acciones, articuladas a través de cuantos actores se consideren oportunos. Actores generalmente diversos (de distintos ámbitos) que pueden ayudar a satisfacer aspectos conectados con la vida (y el mundo) del educando.

Difícilmente la intervención con un menor infractor va a requerir, solamente, un trabajo individualizado de aprendizaje. El proceso no suele ser únicamente educativo, dependiendo del caso, además, necesita ser: familiar, laboral, legal, económico, terapéutico, etc. Dicho de otro modo, para que el proceso pedagógico pueda prosperar adecuadamente, necesita que paralelamente se conjuguen acciones de otra índole.

Como consecuencia, la coordinación entre ellas es un requisito indispensable. La coordinación consiste en la articulación con sentido de las diversas aportaciones. Organizarse de ese modo debe ser un objetivo estratégico (Paricio, 2010) a la hora de poner en marcha este tipo de procesos de intervención tan complejos. Dice Morata (2014, p. 15) que "la corresponsabilidad en todo el proceso educativo resulta clave para posibilitar mayores cuotas de reinserción social".

Si los distintos agentes remasen en la misma dirección, las posibilidades de que el proceso de reforma juvenil se desarrollase de manera adecuada aumentarían. Los distintos agentes involucrados deben ser conscientes de que cada uno juega un papel importante en la evolución del caso y que aunar esfuerzos redunda positivamente en su desarrollo y, por ende, en beneficio del conjunto de la sociedad.

La Ley Orgánica 5/2000, reguladora de la responsabilidad penal del menor, demanda, a cada entidad encargada de materializar medida, un PIEM (Programa Individualizado de Ejecución de Medida) para cada menor. Cuando un proceso de reforma se ha de conformar de más de una medida judicial, dicho PIEM se debería diseñar de manera global, manteniendo una visión de conjunto de todo el proceso de reforma y, por tanto, tratando de evitar una suma de partes inconexas.

En virtud de ello, se demanda longitudinalidad, porque se hace necesario que todas las acciones que conforman dicho proceso de reforma sean coherentes desde el principio hasta el fin.

Es cierto que los departamentos de justicia juvenil de algunas Comunidades Autónomas han creado plataformas virtuales en las que los distintos profesionales intervinientes sobre un caso (de una u otra medida) pueden ir colgando las distintas actuaciones que se van llevando a cabo, por lo que el resto de profesionales tienen la posibilidad de acceder, de manera sencilla, a la evolución del menor durante el proceso. Lo cual, en teoría, posibilita y agiliza el acceso a la información. Sin embargo, el uso de esas plataformas presenta 
algunos problemas (no todos las utilizan, no se actualizan adecuadamente, no se detalla el desarrollo de los procesos pormenorizadamente, etc.), por lo que no garantizan una narrativa fehaciente de las distintas acciones que se llevan a cabo con el menor.

Hay que entender el proceso de reforma como una unidad. Por eso, se requiere continuidad y coordinación durante todo su desarrollo, para velar por el sentido de toda la intervención.

\section{Metodología}

Para llevar a cabo el estudio se utilizó la metodología de investigación biográfica, materializada a través de una Historia de Vida que se desarrolló para la ocasión. Era la metodología que mejor se adaptaba a las necesidades y características del trabajo que se quería llevar a cabo. Entre otras cosas, porque permitía tener una panorámica de toda su vida y comprender la transcendencia que el proceso de reforma juvenil había tenido en su trayectoria (Waller y Simmons, 2009).

El relato biográfico se armó utilizando el modelo de relatos cruzados, tomando las obras de Lewis (1973) y Gamella (1990) como referentes, internacional y español, respectivamente. En dicho modelo:

el personaje central de la narración debido a su singularidad y relevancia, nos ofrece la melodía, mientras los otros relatos nos ofrecen la armonía, el contrapunto, la fuga. Una estructura compleja, que enriquece el relato original, que lo enmarca, lo sitúa en perspectiva y que, a efectos analíticos, separa los factores más idiosincrásicos de la visión de la situación, para restituirnos un discurso multicentrado que gana en profundidad y en objetividad

(Pujadas, 2002, p. 56).

Durante el trabajo de campo se recurrió a una cantidad muy importante de fuentes de información y se utilizaron diversas técnicas para recopilar los datos. Las más destacadas fueron: las entrevistas a Omar, que fueron numerosas y se realizaron desde distintos enfoques; las entrevistas a los 17 personajes clave, que jugaron un papel relevante en el desarrollo de su historia. A continuación, se relacionan trece personas, pero hay varias de ellas que jugaron un doble rol, por eso se cuentan 17 personajes. Por ejemplo: la trabajadora social del centro de internamiento después se convirtió en su jefa, en su actual trabajo. En esos casos, las entrevistas se realizaron atendiendo a esa doble relación que tuvieron con Omar:

- La jueza que llevó el caso;

- Una educadora del Equipo Técnico;

- El subdirector del Centro de Internamiento de Menores Infractores (CIMI);

- La trabajadora social del CIMI, que también era directiva de la Asociación en la que Omar trabaja actualmente;

- El tutor de Omar en el CIMI;

- Una educadora de una de las secciones en las que estuvo durante el internamiento en centro;

- Dos monitores del CIMI y en la actualidad amigos de él;

- Una señora que trabajaba en la lavandería del CIMI que, posteriormente, se convirtió en su madre de acogida;

- La tutora de Omar durante la libertad vigilada;

- Un educador de libertad vigilada;

- Un hermano de Omar;

- Y un compañero de trabajo.

En relación con las fuentes documentales se revisaron: a) el expediente de Omar en el Juzgado de Menores y b) su expediente en la Dirección General de Reforma Juvenil. Y se compiló un registro iconográfico de más de doscientas fotografías, la mayoría de ellas correspondientes a vivencias durante la medida de internamiento en centro, que fue acompañado de una entrevista explicativa. Además de ello, a continuación, se enumeran el resto de fuentes y técnicas a las que se recurrió: 
Tabla 1

Resumen del resto de fuentes de información y técnicas de recogida de datos

- Materiales elaborados:

- Biograma

Sociograma + Entrevista

- DAFO a prácticamente todos los informantes

- Ley Orgánica 5/2000, reguladora de la responsabilidad penal del menor

- Información inesperada: Manuscrito Omar (“Significado de su trabajo”) + Entrevista

- Cuaderno del investigador

- Informe del tutor en el centro de internamiento que no constaba en los expedientes antes citados

- Devolución pre-análisis (a Omar en dos ocasiones y una al resto de personajes secundarios)

Todo ello permitió construir la realidad sujeta a estudio de manera exhaustiva y rigurosa (Bertaux, 2005). El proceso de categorización se llevó a cabo de manera inductiva, sintetizando toda la información hasta completar una estructura de análisis completa que permitía dar respuesta a los dos focos la investigación: 1) Qué ocurrió a lo largo del proceso de reforma para que se produjese aquella transformación en Omar. Y 2) qué tuvo de educativo todo aquel proceso. Se utilizó el programa de análisis de datos cualitativos NVivo para realizar la interpretación y examen de los datos.

\section{Resultados. La trabajadora social del centro de internamiento eje de la buena práctica}

A continuación, se analizan los tres aspectos clave para que aquel proceso de reforma evolucionara de buena manera: acompañamiento sociopedagógico, enfoque holístico y longitudinalidad. Dichos aspectos se van a escudriñar a través de la labor que llevó a cabo la trabajadora social del centro de internamiento, que jugó un papel esencial en la evolución del caso. Su práctica profesional comprende dichos aspectos, combinándolos adecuadamente y con sentido, y a partir de las distintas acciones que desempeña se pueden vislumbrar con claridad.

Dicha profesional fue una de las piezas clave para que la historia de Omar evolucionara como lo hizo. Ella no solo influyó de manera significativa en el desarrollo de la medida de internamiento en centro, sino que fue determinante en la evolución de todo el proceso de reforma juvenil. Y lo fue, porque fue capaz de poner en marcha, desde una perspectiva integral y ecológica, iniciativas de distinta naturaleza que resultaban necesarias para el adecuado desarrollo de la historia. Además, porque fue capaz de trabajar con Omar cuando este cumplía la medida de libertad vigilada, es decir, cuando ya no pertenecía a su centro debido a que estaba cumpliendo otra medida judicial. A ella no le importó esa parcelación y siguió trabajando en pos de su superior interés. Y, por último, por su estilo sociopedagógico, procurador de situaciones y basado en el carácter proactivo del educando durante el proceso. Estilo, que ilustra con claridad la concepción de acompañamiento que se demanda para este tipo de intervenciones.

Aunque la trabajadora social del centro de internamiento puso en marcha diversas iniciativas que resultaron trascendentales para que el caso evolucionara favorablemente, en este apartado se van a examinar, únicamente, las acciones más destacadas que se conjugaron con el propósito de que Omar obtuviese un empleo, que resultó un hito definitivo en el desarrollo de su historia. Concretamente se van a examinar: 1) Diagnóstico certero; 2) Anticipación e Iniciativa; y 3) Valentía profesional, porque a través de ellas se pueden visualizar los tres aspectos clave señalados como eje de la buena práctica. 


\subsection{Diagnóstico certero - Objetivos adecuados.}

La trabajadora social del centro de internamiento realizó un diagnóstico inicial certero. Identificó los verdaderos motivos que habían llevado a Omar al mundo del tráfico de drogas y planteó adecuadamente los objetivos que, desde su parcela y en general, se habían de plantear en la intervención.

En concreto, descubrió que Omar se encontraba en aquella situación porque quería cambiar de vida y había decidido intentar llevar a cabo ese cambio a través de una vía ilícita. Él había nacido en el seno de una familia muy numerosa que disponía de muy pocos recursos y que vivía en unas condiciones muy precarias (de hecho, no tenían ni agua corriente en casa). Y durante su adolescencia se dio cuenta de que estaba destinado a tener una vida similar a la de sus padres, una vida dura completamente distinta a la que sabía que existía al otro lado del mar Mediterráneo. El se enredó en una organización narcotraficante para cruzar la frontera e intentar conseguir esa otra vida. Tanto era así que, como se puede apreciar en el informe inicial de la trabajadora social del centro de internamiento, desde el primer momento expresó su deseo de asentarse de manera definitiva y regularizada en España.

\section{Desenvolvimiento de Omar}

(...) Omar es un chico que desea mejorar y según él manifiesta vino a España con deseos de mejorar dentro de una situación laboral, ya que en Argelia dice que la situación es de gran miseria, pese a que en su casa hay para comer y no se pasan grandes necesidades, pero que dentro de un tercer mundo (...).

\section{Perspectivas de Omar para el futuro}

Omar quiere residir en España, pues considera que en esta, hay más posibilidades

(Informe inicial de la trabajadora social del Centro de Internamiento, Biografía, p. 200)

Fue fundamental comprender que el verdadero objetivo de Omar era migrar y cambiar de vida para determinar el trabajo que había que realizar con él durante todo el proceso de reforma juvenil (no solo durante la medida de internamiento en centro).

\subsection{Anticipación e iniciativa}

La inserción laboral era uno de los objetivos prioritarios que se plantearon con él. Se pretendía que estudiase y obtuviese una titulación académica básica que le permitiese encontrar un empleo. El fin último era que consiguiese un trabajo dentro de los cauces legales que le diese la posibilidad de subsistir dignamente cuando finalizase el proceso de reforma juvenil. Un trabajo que le proporcionara los ingresos necesarios para independizarse y asentarse de manera definitiva en España.

Para ello, en primer lugar, se le inscribió en un centro de enseñanza reglada que había en el propio centro de internamiento. El propósito era que obtuviese el Graduado Escolar. El diploma de estudios básicos suele resultar requisito a la hora de obtener cualquier empleo.

Aunque había una barrera idiomática importante y las tareas académicas, además de no gustarle, le resultaban muy complicadas, Omar hizo un esfuerzo enorme, poniendo todo de su parte para conseguir dicho título.

Área escolar:

Actualmente, el menor recibe clases en nuestro centro, donde se le imparte contenidos en las áreas de lenguaje, matemáticas y conocimientos del medio, donde, presenta una buena actitud en el trabajo, mostrando un nivel de atención y motivación bastante bueno. Este aprendizaje es vulnerable un poco al hándicap del idioma, ya que Omar domina nuestro idioma, aunque no en su totalidad. [Destaca por su] constancia y por su motivación en el aprendizaje del día a día. (...) En la sección se realizan tareas de apoyo escolar de forma diaria, desarrollándolas de forma adecuada, destacando por su motivación y por la demanda de realizar más actividades de las que se le proponen.

(Informe inicial Equipo Educativo, Biografía, pp. 203-204) 
Omar tenía claro que quería completar la formación reglada satisfactoriamente. Las evidencias destacan la determinación y motivación que mostraba al respecto. Se lo tomó tan en serio que pedía a sus educadores que, además de los ordinarios, le pusieran deberes extra.

Con el objetivo de regularizar la situación de ciudadanía de Omar en España, era necesario iniciar los trámites para conseguirle los permisos de trabajo y residencia. Varios meses antes de que le fuese sustituida la media de internamiento por la de libertad vigilada, la trabajadora social del centro de internamiento se desplazó con él al consulado de su país, para recopilar documentos que les requerían a la hora inscribirlo en la oficina de empleo. Con ellos le consiguieron el pasaporte y sacaron la tarjeta de demanda de empleo.

Un día tuvimos que ir [al consulado] (...). Total, nos dieron nuestra documentación, nos vinimos con nuestro pasaporte. A través del pasaporte buscamos la residencia. Ya teníamos la residencia, teníamos el pasaporte, era mayor de dieciséis años, sacamos el tema del paro y ahora vamos a ver dónde te vamos a enganchar a trabajar

(Trabajadora social del centro de internamiento, Biografía, p. 216).

Paralelamente a ello, con parte del dinero que nuestro protagonista atesoraba (de cuando trabajó para la organización traficante), Omar contrató los servicios de una letrada para que se dedicara específicamente a regularizar su situación de ciudadanía en España. Nuestro protagonista no solo iba cumpliendo con lo que se le demandaba por parte de los distintos profesionales, además él tomaba iniciativas que contribuían a la evolución de su proceso.

Después del juicio, con "el dinero que tenía todavía por ahí, que no había gastado, se cobró el abogado que me estaba defendiendo en ese momento y otra abogada que era la que me arregló los papeles. Ella lo tuvo todo fácil, además cobró prácticamente por toda la cara (...), la tutela la tenía la Junta de Andalucía, yo era un niño de la Junta. Todo era fácil. Legalmente solo tenía que juntar las piezas, y las tenía todas"

(Omar, Biografía, p. 133).

La residencia temporal y la autorización para trabajar (con periodo de vigencia de un año) se obtuvieron en un plazo aproximado de seis meses.

También fue matriculado en un programa de Formación Profesional Básica de pintura que se impartía en el mismo centro de internamiento. Hay que poner de manifiesto que poco después de iniciar dicho curso, Omar concluyó la medida de internamiento en centro y pasó a libertad vigilada, por lo que dejó de residir en dicho centro. Sin embargo, regresaba a él cada día para completar el curso de pintura, lo que mostraba diversas actitudes que fueron determinantes en el desarrollo de su caso (responsabilidad, compromiso, tesón, etc.).

Estando de libertad vigilada volvía al centro de internamiento a terminar los estudios porque me quedaba el curso de formación profesional por terminar, era un curso de pintura. Yo estaba fuera, no estaba en el centro, pero venía al centro a estudiar (...). Los niños me decían que qué tonto que estando fuera tener que venir al centro.

(Omar, Biografía, p. 116).

Cuando el curso de formación profesional concluyó, el centro de internamiento (del que él ya no formaba parte) le propuso como candidato para una oferta de empleo que había realizado una empresa de rehabilitación de edificios. Así fue como empezó a trabajar.

Lo enganchamos en un curso de pintura que había en el centro y empezó a pintar, claro yo también siempre he confiado en que él cumpliera con su parte. Él hizo el curso de pintura y lo contrataron para pintar.

(Trabajadora social del centro de internamiento, Biografía, p. 216).

Todo iba encajando y posibilitando la adecuada evolución del caso porque, previamente, se habían iniciado las acciones necesarias. Fundamentalmente, era la trabajadora social del centro de internamiento quien, de manera holística y con sentido, iba anticipando los peldaños que posibilitaban el camino. 


\subsection{Valentía profesional}

Algún tiempo después de que finalizara la experiencia laboral como pintor y faltando pocos meses para que concluyese la medida de libertad vigilada y, por consiguiente, el proceso de reforma juvenil, se le ofertó un trabajo que marcaría definitivamente el devenir de su historia. La trabajadora social del centro de internamiento también era directiva de una asociación que se encargaba de materializar medidas de protección de menores. Por aquel entonces surgió una vacante de monitor en dicha asociación y concurrían las circunstancias para que se le pudiese ofrecer el empleo a Omar.

En aquella época, había un piso tutelado con una población importante de niños y adolescentes un tanto complicados que eran de origen marroquí. Necesitaban a una persona árabe que pudiera contribuir a reconducir una situación que parecía haberse ido un poco de las manos, desde un punto de vista comportamental, y, al parecer, Omar tenía un perfil que podía cubrir esas necesidades.

Aunque la trabajadora social ostentaba un cargo directivo en dicha asociación tomó cierto riesgo al proponer a nuestro joven protagonista para aquel trabajo. Políticamente, no parecía muy adecuado que "un menor infractor", con antecedentes de tráfico de estupefacientes, desempeñase profesionalmente una labor social y formativa con niños y chicos en situación de "protección". Socialmente podía resultar una decisión muy controvertida. Sin embargo, la trabajadora social del centro de internamiento decidió seguir adelante, haciendo un alarde de valentía y determinación sociopedagógica.

Yo toda mi obsesión era buscarle una salida un poquito de más nivel, porque yo veía que cara a los niños él sabía perfectamente manejar situaciones difíciles, su experiencia le servía positiva (...). Y yo me la jugué, me la jugué porque decía: «A nadie le puedo contar ni que viene del centro de reforma, ni que viene de un tráfico de drogas, ni que viene de todas estas historias». Y como yo mandaba, porque éramos dos personas las que habíamos puesto la asociación en la ciudad. Hacía falta un monitor en un piso y se lo dije a la presidenta, digo: «Tengo un chico que es argelino, hay un piso que es muy difícil»", había marroquíes muy difíciles, yo tenía que tener un árabe allí, pero vamos que si no, lo meto en otro lado (...). Y también quería que él fuera conociendo otras cosas, que fuera viendo si podía buscar trabajo, porque tampoco lo quería yo encasillar. Entonces, le dije a la presidenta: «creo que va a poner orden en el piso tal». Ese piso estaba totalmente disparado. Y se lo ofrecí. Le dije: «No vas a ganar mucho, pero vas a tener un trabajo mejor que pintando fachadas».

(Trabajadora social del centro de internamiento, Biografía, p. 303)

Tal y como muestra la evidencia, no solo se le quería proporcionar un puesto de trabajo, sino que, además, se quería que ampliase el rango de posibilidades laborales que hasta ese momento estaba barajando.

Tomar contacto con otro tipo de ocupaciones le abría la puerta a otras profesiones y, en consecuencia, a otras formas de vida. En concreto, el puesto ofertado en el ámbito de protección de menores le permitía poder construir un proyecto de vida en torno a la educación social.

En cuanto a su futuro laboral, bueno pues eso es simple, la trabajadora social del centro fue la fundadora de una asociación de protección de menores, y en este caso pues ella propuso que Omar pudiera incorporarse, dado su valor, dada su experiencia tanto vital como personal, a que pudiera ayudar a chavales desfavorecidos por el entorno familiar..., chicos de protección, temas de abandonos, temas de... Y efectivamente ese fue el inicio de Omar, es decir, su andadura dentro de lo que es la educación, es decir, trabajar como monitor en un centro donde había chavales con necesidades, sobre todo de tipo afectivo. Y efectivamente empezó a funcionar con un criterio de madurez muy alto, con un criterio normativo y moral muy claro, pero a la vez con la capacidad de afecto. Muy llamativo. De hecho, se convierte en el educador líder de su grupo de chavales, de niños, y un magnífico compañero de cara a los educadores que trabajaban allí. Y de hecho continúa trabajando allí.

(Subdirector del centro de internamiento, Biografía, p. 275)

Desde el primer momento Omar encaja en aquel trabajo y se desenvuelve de manera satisfactoria. Tanto, que transcurrido algún tiempo llega a convertirse en uno de los profesionales de referencia de aquel piso. En la actualidad, más de tres lustros después, continúa trabajando para aquella asociación, desde hace muchos años desempeñando labores de educador. 
Por otra parte, la trabajadora social del centro de internamiento sabía que con aquel contrato posibilitaba que Omar regularizase su situación, de manera permanente, en España, ya que le permitía obtener un permiso de residencia definitivo y, por consiguiente, estabilizarse legalmente de manera irreversible.

La trabajadora social del centro de internamiento sabía que los papeles que a mí me han dado la primera vez eran de un año, pero para renovarlos necesito un contrato. Entonces claro, yo estaba mirando a ver cómo puedo hacer aquello y ella pues me ha buscado ese trabajo para que pueda renovar. Yo ya tenía los papeles, simplemente cuando llega la hora de la renovación de la primera residencia te exigen que estés trabajando. Si tú no tienes un contrato para la renovación, entonces tú has venido temporal a trabajar, tu contrato ya ha acabado, entonces deberías de irte. Pero si tú tienes un contrato que sea de trabajo, sí te puedes seguir estando (...). Nada, que también ella sabía eso y sabía que yo buscaba trabajo. Entonces claro, me ha venido bien, todo eso me ha venido seguido porque al pasar allí pues ya no tuve problemas ni nada, todo lo que me han pedido de la empresa lo di y ya se ha quedado todo claro. La primera vez ya lo había arreglado la abogada (...). Lo que era más difícil es lo que se había llevado más dinero. La segunda vez con solo tener un contrato de trabajo ya puedes renovar sin ningún problema

(Omar, Biografía, pp. 119-120)

Que nuestro protagonista encontrase un empleo adecuado resultaba clave en el desarrollo de su proceso de reforma. No solo porque la suficiencia económica se consideraba un elemento fundamental de emancipación, sino porque, además, estimulaba su desarrollo social y su adaptación a las normas de la comunidad. Si Omar encontraba una dedicación que le satisfacía resultaba más sencillo su establecimiento de manera lícita. De lo contrario, no sabemos si habría vuelto a trabajar para la mafia.

Aquel empleo no solo le proporcionaba un salario y posibilidades de subsistencia, además, le otorgaba cierto reconocimiento social, lo que agradaba particularmente a nuestro protagonista. Su familia y su entorno (particularmente de origen) se lo reconocían, pues había conseguido su objetivo migratorio con creces. No se puede olvidar que, en esencia, su historia es la de un joven que quería promocionar socialmente.

\section{Conclusiones}

En virtud de los resultados, se puede decir que los tres elementos analizados en este artículo pueden contribuir al desarrollo de una buena práctica, pues tienen una trascendencia básica en la evolución socioeducativa de casos complejos de menores infractores, de menores en situación de riesgo o de cualquier otro colectivo en circunstancias similares.

El acompañamiento resulta fundamental en este tipo de casos. La concepción de acompañamiento sociopedagógico que en este artículo se ha esbozado así lo ha demostrado. El apoyo y el estímulo son los dos rasgos básicos que lo caracterizan. Proporcionar un soporte al educando en los momentos complicados resulta esencial si se quiere completar el proceso de un modo adecuado y resiliente. En ese sentido, establecer una relación educando-acompañante basada en la confianza resulta indispensable. Por otra parte, el profesional debe ser un procurador de situaciones y momentos incitadores que persigan la transformación personal y ambiental del individuo.

Y es que la intervención debe tener naturaleza holística. Por un lado, debe realizar un abordaje pedagógico, para que el educando aprenda aquello que se establezca como objetivo. Y, por otro, monitorizando y actuando sobre todos aquellos factores que estén poniendo en riesgo su adecuada evolución. Transformar las circunstancias del sujeto es tan o más importante que hacerle desarrollar alguna estructura cognitiva nueva. Dicha transformación modifica los influjos que recibe y puede posibilitar su avance. Por consiguiente, los profesionales no deben poner el foco, únicamente, sobre el sujeto, sino que, además, deben tratar de ayudarle a reconfigurar la situación que le ha llevado hasta allí. Nótese que es el sujeto quien debe cambiar su realidad, no los profesionales que le acompañan.

Como consecuencia, el acompañante debe saber cuándo y cómo actuar porque, por un lado, debe ir un paso por delante en todo el proceso, previendo qué puede resultar necesario, para implementarlo y/o poner en marcha las acciones oportunas. $\mathrm{Y}$, por otro, debe saber ubicarse un paso por detrás del educando, para permitirle protagonizar la experiencia. Independientemente del lugar en el que se encuentre, el educando debe sentir su apoyo en todo momento.

El proceso de reforma juvenil es una única intervención, no un proceso balcanizado en el que se yuxtaponen distintas actuaciones de manera inconexa. La interseccionalidad de la intervención requiere de sentido entre 
las distintas acciones. Por eso, cada agente debe realizar su trabajo comprendiendo que su labor es un elemento más del ecosistema que configura el proceso. Esa labor se ha de coordinar, intentando que exista coherencia entre todas ellas. La evolución del caso depende, en gran parte, de ello. Sin embargo, no existe una figura que vele por el buen desarrollo de todo el proceso de reforma juvenil cuando este se compone de más de una medida judicial. La figura de un profesional que cubriese el periodo completo, de manera longitudinal, teniendo una panorámica de todo el proceso, resultaría beneficiosa en muchas intervenciones, fundamentalmente, en aquellas que resultan más complejas. Como se ha podido ver, eso es lo que hizo la trabajadora social del centro de internamiento, que se erigió en esa figura transversal que aquí se está reivindicando.

\section{Referencias}

Alonso, I. y Funes, J. (2009). El acompañamiento social en los recursos socioeducativos. Educación Social, 42, 28-46. Batlle Rois, F. A. (2010). Acompañamiento docente como herramienta de construcción. Revista Electrónica de Humanidades, Educación y Comunicación Social, 8, 102-110.

Bertaux, D. (2005). Los relatos de vida. Perspectiva etnosociológica. Barcelona: Edicions Bellaterra.

Biagioli, R. (2018). Educadores de profesión. El papel de los educadores en los servicios sociales. En R. Biagioli, J. González-Monteagudo \& C. Petruzzi (Eds.), Papel y formación de los educadores. Pedagogía y metodologías para las comunidades de acogida de menores extranjeros no acompañados (pp. 101-118). L'Harmattan.

Boroel Cervantes, B.I., Sánchez Santamaría, J., Morales Gutiérrez, K.D., \& Henríquez Ritchie, P.S. (2018). Educación exitosa para todos: la tutoría como proceso de acompañamiento escolar desde la mirada de la equidad educativa.

Revista Fuentes, 20(2), 91-104.

http://dx.doi.org/10.12795/revistafuentes.2017.v20.i2.06

Bowlby, J. (1976). El vínculo afectivo. Paidós.

Colom Cañellas, A.J., \& Núñez Cubero, L. (2001). Teoría de la Educación. Síntesis.

García-Pérez, A., \& Mendía, R. (2015). Acompañamiento educativo: El rol del educador en aprendizaje y servicio solidario. Profesorado. Revista de currículum y formado del profesorado, 19 (1), 42-58.

Gamella, J.F. (1990). La historia de Julián. Memorias de heroína y delincuencia. Popular.

Ghouali, H. (2007). El acompañamiento escolar y educativo en Francia. Revista Mexicana de Investigación Educativa, 12(32), 207-242.

Herrera Pastor, D., \& De Oña Cots, J.M. (2017). Personalizar la intervención educativa con menores en situación de riesgo es fundamental para su desarrollo, la igualdad de oportunidades y la justicia social. Revista Internacional de Educación para la Justicia Social, 6 (2), 149-165.

https://doi.org/10.15366/riejs2017.6.2.009

Herrera Pastor, D., \& De Oña Cots, J.M (2016). La importancia del ambiente de aprendizaje. Pedagogía ecológica en un centro de menores. Revista Fuentes, 18 (1), 77-90.

http://dx.doi.org/10.12795/revistafuentes.2016.18.1.05

Konstantoni, K., Kustatscher, M., \& Emejulu, A. (2017). Travelling with intersectionality across time, place and space.

Children's Geographies, 15, 1-5. https://doi.org/10.1080/14733285.2016.1255838

Ley Orgánica 5/2000, reguladora de la responsabilidad penal del menor. BOE № 11 de 12 de enero de 2000 (14221441).

Lewis, O. (1973) Los hijos de Sánchez. Autobiografía de una familia mexicana. Joaquín Mortiz.

Martínez Reguera, E. (2012). Esa persona que somos. Ed. Popular.

Morata, T. (2014). Pedagogía Social Comunitaria: un modelo de intervención socioeducativa integral. Educación Social. Revista de Intervención Socioeducativa, 57, 13-32.

Navarro, J.J., Uceda, F.X., \& Pérez, J.V. (2014). El acompañamiento cotidiano como recurso educativo en la intervención con adolescentes. RES. Revista de Educación Social, 18 (VI Congreso Estatal de Educación Social | Eje temático 3: Experiencias de futuro. Nuevos campos y líneas de ruptura en la educación social), 1-16.

Ortega y Gasset, J. (1914). Meditaciones del Quijote. Publicaciones de la residencia de estudiantes.

Paricio, J. (2010). El reto de institucionalizar la coordinación e integración docente. En J. Rué y L. Lodeiro (Eds.), Equipos docentes y nuevas identidades académicas (pp. 21-43). Narcea.

Planella, J. (2008). Educación social, acompañamiento y vulnerabilidad: hacia una nueva antropología de la convivencia. Revista Iberoamericana de Educación, 45 (5), 1-14.

Puerta Gil, C.A. (2016). El acompañamiento educativo como estrategia de cercanía impulsora del aprendizaje del estudiante. Revista virtual Universidad Católica del Norte (Colombia), 49 (septiembre-diciembre), 1-6.

Pujadas Muñoz, J.J. (2002). El método biográfico: El uso de las historias de vida en ciencias sociales. Centro de Investigaciones sociológicas.

Vallés Herrero, J., \& Pérez Juste, R. (2015). Las funciones del educador social. Validación del cuestionario CFES-R.

Bordón, 67(2), 131-153.

https://doi.org/10.13042/Bordon.2015.67209

Vygotsky, L. S. (1962). Thought and language. MIT Press. 
$\ldots$

Waller, R., \& Simmons, J. (2009). Vidas a través de la lente de un ojo de buitre: Interpretando cuentos de aprendices. En J.I. Rivas Flores, \& D. Herrera Pastor (Coords.), Voz y educación. La narrativa como enfoque de interpretación de la realidad (pp. 55-74). Octaedro. 